Natural Hazards and Earth System Sciences, 5, 375-387, 2005

SRef-ID: 1684-9981/nhess/2005-5-375

European Geosciences Union

(c) 2005 Author(s). This work is licensed

under a Creative Commons License.

\title{
Evolution of natural risk: research framework and perspectives
}

\author{
G. Hufschmidt ${ }^{1}$, M. Crozier ${ }^{1}$, and T. Glade ${ }^{2}$ \\ ${ }^{1}$ School of Earth Science, Victoria University Wellington, PO Box 600, New Zealand \\ ${ }^{2}$ Department of Geography, University of Bonn, Meckenheimer Allee 166, Bonn, Germany
}

Received: 24 February 2005 - Revised: 22 April 2005 - Accepted: 22 April 2005 - Published: 4 May 2005

\begin{abstract}
This study presents a conceptual framework for addressing temporal variation in natural risk. Numerous former natural risk analyses and investigations have demonstrated that time and related changes have a crucial influence on risk. For natural hazards, time becomes a factor for a number of reasons. Using the example of landslides to illustrate this point, it is shown that: 1 . landslide history is important in determining probability of occurrence, 2 . the significance of catchment variables in explaining landslide susceptibility is dependent on the time scale chosen, 3. the observer's perception of the geosystem's state changes with different time spans, and 4. the system's sensitivity varies with time. Natural hazards are not isolated events but complex features that are connected with the social system. Similarly, elements at risk and their vulnerability are highly dynamic through time, an aspect that is not sufficiently acknowledged in research. Since natural risk is an amalgam of hazard and vulnerability, its temporal behaviour has to be considered as well. Identifying these changes and their underlying processes contributes to a better understanding of natural risk today and in the future. However, no dynamic models for natural risks are currently available. Dynamic behaviour of factors affecting risk is likely to create increasing connectivity and complexity. This demands a broad approach to natural risk, since the concept of risk encapsulates aspects of many disciplines and has suffered from single-discipline approaches in the past. In New Zealand, dramatic environmental and social change has occurred in a relatively short period of time, graphically demonstrating the temporal variability of the geosystem and the social system. To understand these changes and subsequent interactions between both systems, a holistic perspective is needed. This contribution reviews available frameworks, demonstrates the need for further concepts, and gives research perspectives on a New Zealand example.
\end{abstract}

Correspondence to: G. Hufschmidt

(gabi.hufschmidt@vuw.ac.nz)

\section{Introduction}

Wright (2004), in the Massey Lectures, estimates that since the year 1900 the world's population has increased four times while economic activity has increased forty times. Our world is changing at a rapid pace; a dynamic, interactive construction emerges, driven by both geophysical and social forces (Etkin, 1999; Mileti, 2004). Because new structures evolve offering a greater potential for interaction, enhanced connectivity between physical and social systems develops from these dynamics. For example, on a global level, demand (social system) for land as a resource (geosystem) has increased dramatically: between 1850 and 1980 cropland tripled worldwide - and without the ability to intensify production this increase would have been even greater (Goudie, 1993). Rising connectivity is likely to entail higher complexity. As Mileti (1999) points out, growing hazard-related losses in the USA are a result of this increasing complexity, and not solely related to the behaviour of natural processes.

Connectivity between physical and social systems is a fundamental characteristic of natural risk. Hence, the representation of natural risk cannot rely on one theory or discipline alone. Indeed, it encapsulates a huge range of research fields. Mutual understanding between disciplines is difficult. Would it not be useful to have a "babel-fish" in our ears, translating all spoken languages (Adams, 1989)?

The term "natural risk" is used within this paper to distinguish risk related to geophysical processes from technological or economic risks. It is recognised that this term, as well as the term "natural disaster", is criticised by some social scientists because of the connotation of nature intentionally harming humans (Glade, 2003b). But clearly within nature there is no mind that determines processes. Therefore, nature cannot be attributed with intention, nor has it a system of value to judge processes (Leilich, 2003).

The notion "system" is used in the sense of a holon, which Koestler (1967) introduced to biology. Haigh (1987) offers the following definition: "A holon is any stable sub-whole in a hierarchy. It is a self-creating, open system". Von Berta- 
lanffy (1950) stated that open systems are characterised by an import and export of material and energy, which is required for self-maintenance or a "steady state". A geomorphological system (within a geosystem) "is a structure of interacting processes and landforms that function individually and jointly to form a landscape complex" (Chorley et al., 1984). An example is a drainage basin, with input, transfer and output of energy and mass, connecting subsystems of different hierarchical levels. Another example is the national urban system of interrelated cities and towns, which can have a varying degree of openness or closure (Pacione, 2001). This goes back to the theory of central places by Christaller (1966), illustrating the hierarchy of cities and towns based on their functionality within a spatial network of infrastructure and goods. Today, the hierarchical system of central places spreads worldwide, with global cities such as Tokyo and New York on the highest level within a "transnational urban system" (Sassen, 1994), connected by flows of capital, labour, and goods.

The term "evolution" has different associations; while some may use it in the sense of a gradual development through time, others imply a gradual but also inevitable and irreversible process. In earth science, inspired by Charles Darwin, the paradigm of the "cycle of erosion" by W.M. Davis $(1899,1909)$ dominated the scientific landscape. Davis considered landscape evolution as a development from "youth" to "maturity" and "old age", focussing on the passage of time as the main agent. A similar construct emerged in Human Geography, based on the work of Spencer (1872) and Spengler and Atkinson (1926), who regarded societies as organisms completing a cycle of life. In earth science, Davis's paradigm was criticised as too general. "General systems theory" successfully challenged the paradigm in the 1950s/1960s (Chorley, 1962), relying on the introduction of open systems by von Bertalanffy (1950) as mentioned above, and "grade " or dynamic equilibrium by Gilbert (1877), complex response and thresholds. Rather than seeing time as a process itself, time-independence is postulated: open systems reach an equilibrium in which the system's state is preserved by a throughflow of energy and by negative feedbacks (Chorley et al., 1984; Hack, 1960). Different kinds of equilibriums are e.g.: steady state (stable average value), dynamic (gradually changing average value) or dynamic metastable (changing average value interrupted by discontinuous impacts or threshold crossings) (Chorley et al., 1984). As in earth science, within Human Geography the understanding of societies completing a cycle of life was challenged by the notion of ecological systems, which are characterised by an interaction between people, and by people with their biophysical environment. The system is an adaptive, hierarchical structure of subsystems (or holons), connected by fluxes of energy and information, creating a dynamic equilibrium at every level and the system as a whole (Butzer, 1996).
A basic conflict between open system's time-independent thinking, and evolution as an inevitable succession dependent on the passage of time becomes apparent: The first does not fully acknowledge progressive system change (e.g. relief reduction), the latter is not flexible enough to meet complex system's behaviour. As will be seen later on (Sect. 2.1.1.), the concept of different time spans governing a system's state offers a solution to this conflict. While a steady state is likely to be established at shorter time scales (and for smaller areas), its utility is limited to long-term (and small scale) analysis. Although the equilibrium concept supports the understanding of system's behaviour, historic perspectives are also needed (Hack, 1960; Schumm, 1977; Schumm and Lichty, 1965).

This is a conceptual paper, that critically evaluates current risk assessment frameworks with respect to temporal changes and that aims to develop new strategies and concepts to incorporate complexity in temporal behaviour. Exploring time dependency of risk is the motivation for a more comprehensive understanding of the dynamics and controls of risk. Throughout this paper natural hazard and risk are illustrated by landslides as an example. This is done in order to demonstrate the relevance of these concepts to real world situations. New Zealand has been chosen as a context within which to explore the evolution of risk for two reasons: First it is subject to a high level of natural hazard; second it has experienced dramatic environmental and social changes within a relatively short period.

\section{Motivation}

\subsection{Dynamics and connectivity}

Assessing risk associated with natural hazards is generally based on a static approach. Commonly, risk levels are calculated for a particular moment in time, while past risk levels are unknown. However, identifying temporal changes of natural risk, as well as the underlying processes, contributes to an improved understanding of today's risk levels.

\subsubsection{Natural hazards and landslides}

"Natural hazard" as used here, is a condition that expresses the probability of a damaging event occurring with a specified magnitude within a defined time period and area (Crozier, 1993; IUGS Working Group on Landslides - Committee on Risk Assessment, 1997). The term landslide defines a gravitationally directed movement of rock, debris or soil, e.g. a rockfall or debris flow (Crozier, 1999; Cruden and Varnes, 1996; Dikau et al., 1996). Landslides, as processes within geosystems, pose a threat to those elements of the social system exposed or indirectly affected.

As stated earlier, the focus of this paper is an analysis of the time dependency of risk. With respect to geosystems in general and landslides in particular, the following issues are considered time dependent and critical controls of risk. 


\section{Process history affects hazard potential}

Understanding geosystem behaviour requires the knowledge of the system's history. Factors controlling instability can change with time. For example, a catchment that has been deforested for pasture farming has enhanced susceptibility to landslide occurrence; conversely, susceptibility can be decreased with reforestation.

Once an area is affected by landsliding, it might become a permanent source of hazard (Crozier and Glade, 1999; Reimer, 1995). It is common practice to interpret the presence of landslides within a system as representing an on-going, characteristic and immutable level of hazard. In unstable systems, however, this would require a state of equilibrium which is likely to persist for only relatively short periods of time. Slope instability tends to be cyclic. It is, in the long term, a self annihilating process; because the process (by reducing slope height or angle, or by exhausting susceptible material) destroys the conditions for its occurrence. In this case, the landslide process itself stabilises the terrain, as demonstrated by examples in New Zealand by Crozier and Preston (1998) and Preston (1999). In terms of identifying future hazard, it is, therefore, essential that the "stage" of the instability cycle is identified - and that can only be achieved by taking a historical perspective.

\section{The period of observation determines the function of variables within a geosystem}

The function of a variable is determined by the chosen observation period: e.g. in some instances reversing from a cause (independent) to an effect (dependent) in terms of its contribution to system behaviour. For example, referring to changes of drainage basin variables, during "cyclic time" time, (10 million years), lithology and climate are independent, while vegetation is dependent, as are hillslope morphology and sediment yield. Within shorter "graded time" (1 million years) vegetation shifts to independency, while hillslope morphology and sediment yield are still effects of other variables, and are therefore dependent. Finally, "steady time" is even shorter (1000-100 years), and here nearly all parameters gain independence, except sediment yield. This theory of changing dependency of geosystem variables, introduced by Schumm and Lichty (1965), (see also Schumm, 2003), is important when trying to understand landslide behaviour. The exact temporal periods and variables of the examples given above do not matter in the context of this paper; the point is that the significance of catchment variables in terms of landslide susceptibility changes with the time span chosen: which variable is cause - which is effect?

The chosen time span determines the state of equilibrium perceived by the observer

Again, we face the terms of cyclic, graded time and steady time, with decreasing lengths, respectively. A channel

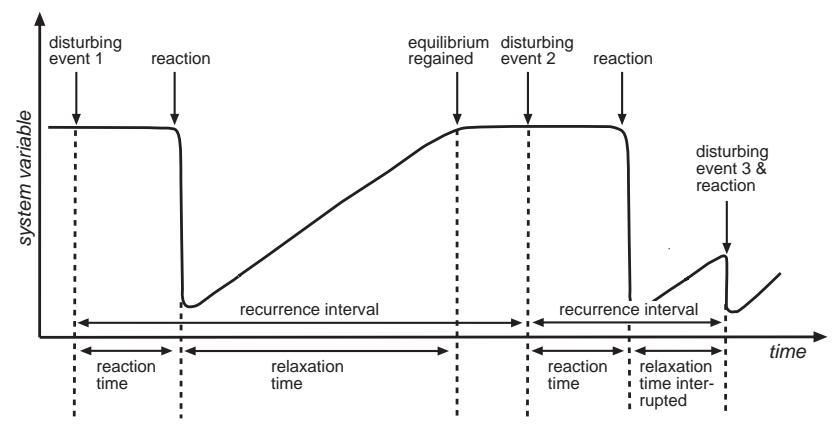

Fig. 1. Reaction and relaxation time after Graf (1988) and Brunsden and Thornes (1979).

gradient e.g. decreases through cyclic time with oscillations around a mean value. Looking at graded time, one might only see one of the oscillations; therefore it is not clear if the gradient follows a pattern or trend. Finally, a much shorter time frame creates the perception of a static gradient, with no change recognisable (Chorley and Kennedy, 1971; Schumm and Lichty, 1965). Dependent on the chosen time span, the observer sees different system states, which leads to different interpretations of landslide behaviour.

\section{Time is an important factor of geosystem sensitivity}

A landslide can be understood as the symptom of a sensitive system. The time span required for a system to recover and gain a new equilibrium after a disturbance such as a landslide, is divided into "reaction time" and "relaxation time". While "reaction time" encapsulates the amount of time between disturbance and related response of the system, "relaxation time" comprises the time between system reaction and achievement of a new equilibrium (Fig. 1). However, in some cases the length of time until reaction is such that the actual cause is blurred (Glade, 2001). Transient states persist if the relaxation time is longer than the recurrence interval of disturbance is, i.e. the system is in a constant sensitive state without reaching a new equilibrium (expressed by the "transient-form ratio") (Brunsden and Thornes, 1979).

Often, slopes are classified as either "stable" or "unstable", which is a simplification requiring considerable qualification before it is applicable. It is more realistic to assess slopes on a spectrum ranging from "stable", to "unstable" (marginally stable) and "actively unstable". If the margin of stability (i.e. excess of shear strength over shear stress) is high enough, all transient triggering forces are neutralised and the slope is stable. Unstable or marginally stable slopes are subject to failure at some point in time when transient forces are sufficiently active. Actively unstable slopes are characterised by movement due to transient forces acting. A temporal shift along the spectrum of the three states can be related to changes in both susceptibility and the energy levels of transient triggering factors. Preparatory factors can push a stable slope into a marginally stable state by enhancing susceptibility, but without causing movement directly. Trigger- 


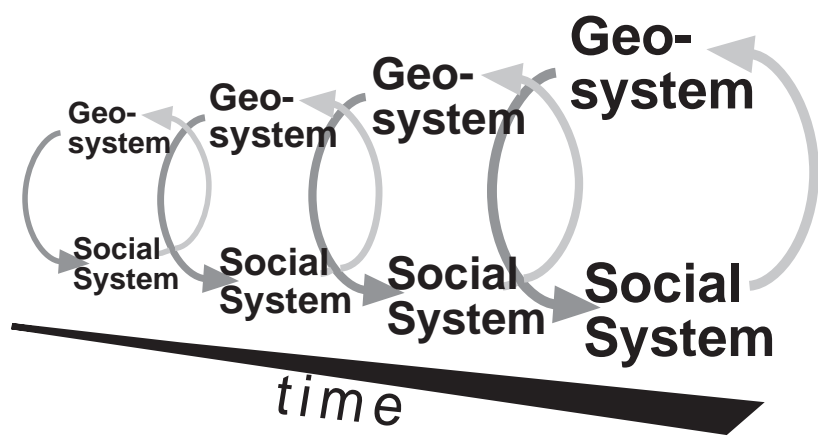

Fig. 2. System interaction through time.

ing factors initiate movement and make a slope actively unstable. Finally, controlling factors govern the form, rate and duration of movement (Crozier, 1986).

Thresholds, which have to be crossed before a reaction can follow, can be assigned to internal or external factors, either imbedded within the system configuration or as part of external systems influencing the geosystem from outside (Schumm, 1979). In a highly sensitive system, small external seismic or climatic triggers can foster a reaction, such as a landslide, while a non or low sensitive system possesses a buffer capacity, and no or little reaction will result (Brunsden and Thornes, 1979; Schumm, 1979; Schumm, 1991; Thomas, 2001). This is a source of non-linearity. The system's state of sensitivity is variable in time, because thresholds change with time, as the example of sediment exhaustion above demonstrates.

In terms of landslides the crucial questions are: How far away is the system from its internal threshold and when will the next external disturbance occur with the power of destabilising the system?

A frequency-magnitude relation of landslide occurrence reflects patterns of landslide behaviour. In general, highfrequency events are of a smaller magnitude than lowfrequency events. Wolman and Miller's (1960) aim was to find the "dominate discharge" which is responsible for most of geomorphological work done in the temporal record. Crozier (1986) and Glade (1998, 2000) established rainfall thresholds for the triggering of shallow landslides in several regions in New Zealand. Based on the rainfall threshold, landslide probabilities for precipitation patterns can be derived. Reid and Page (2002) related the magnitude, in this case the number of landslides triggered, with a certain amount of rainfall for a specified area and observation period. Subsequently, probable landslide magnitudes can be assigned for historical rainfall records. Thresholds and frequency-magnitude relations are important methods of landslide hazard estimation.

Progress is being made within the frequency and magnitude debate, but many questions remain unsolved. Compared to streamflow, landslides are a less steady process, so recording periods have to be longer in order to gain a reliable database. Challenges are great, since data recovery declines with time: evidence of smaller landslides might be destroyed or not recognised. Additionally, non-linear behaviour inand outside the geosystem complicates the understanding of frequency-magnitude relationships. Within a landscape affected by landslides, the original triggering conditions are altered by the process itself; landslides within surficial material cause sediment exhaustion, and triggering thresholds change with time. Therefore, the magnitude of landslides initiated by a specific rainstorm or earthquake can be temporarily variable (Crozier and Glade, 1999). Moreover, the question of the best achievable time span to represent system behaviour today or within a future time period, is critical.

The majority of recent research on natural hazards deals with the current situation. Maps of landslide distribution or terrain susceptibility often show spatial variability only for a snapshot in time. These maps commonly serve as basis for regional planning, but do not contain an indication of temporal dynamics within the geosystem. Landslide hazard maps, as opposed to susceptibility maps, include a temporal component through the consideration of frequency and magnitude of events, but still aim to illustrate the current situation rather than showing temporal variability of hazard.

Natural hazards can no longer be seen as single, isolated events; rather they are complex features reflecting the interaction between geosystems and social systems (Cutter, 1996a). Because the social system evolves and changes, it imposes (new) demands on the geosystem to the extent of changing the landscape and even provoking a physical response, such as a landslide, which in turn fosters a reaction of the social system. The same holds true for geosystems (Fig. 2). Landslides interfering with the human sphere cause reaction, and in turn the results of social response may change the state of the environment.

\subsubsection{Vulnerability}

The vulnerability concept was introduced in the mid 1970s. Cutter (1996b) lists eighteen different expressions of this concept which have appeared in the literature since 1980.

Basically, two different ways of understanding vulnerability are currently dominant: one emerges from natural and engineering science, one from social science. In general, engineers relate structural vulnerabilities to this term only (e.g. building structures, bridge designs, etc.). Natural scientists extend this view by using the term to describe the susceptibility of people, infrastructure and buildings with respect to a hazard. The consequences of a hazard are emphasised, and usually understood as the degree of loss (damage ratio). A scale from 0 (no loss) to 1 (total loss) represents the level of damage (Varnes, 1984). Expressions are usually in terms of monetary values or the probability of lives lost (Glade, 2003b). In contrast, social science focuses on the vulnerability of people. As Wisner et al. (2004) state: "By vulnerability we mean the characteristics of a person or group and their situation that influence their capacity to anticipate, cope with, resist and recover from the impact of a natural hazard. [...] It involves a combination of factors that determine the de- 
gree to which someone's life, livelihood, property and other assets are put at risk by a discrete and identifiable event (or series or "cascade" of such events) in nature or in society". The authors highlight the term livelihood, which they use to develop a model of access to resources, like money, information, cultural inheritance or social networks, influencing people's vulnerability.

The definition of Wisner et al. (2004) corresponds with the way "resilience" is understood today. Within the last decade, the notion of vulnerability in terms of damage and loss, shifted towards the resilience of communities (Omar and Alon, 1994; Paton, 2004). Resilient communities are defined as "structurally organized to minimize the effects of disasters, and, at the same time, have the ability to recover quickly by restoring the socio-economic vitality of the community" (Tobin, 1999). Resilience takes into account community-inherent resources and competence of support coping mechanisms. Therefore, identification of factors strengthening resilience is becoming more and more important (Paton et al., 2003).

The definition of vulnerability by Wisner et al. (2004) cited above includes different time dimensions: phases such as awareness of natural hazards and preparedness, coping during the hazard, as well as recovering, all differ in length. Anticipation, preparedness and recovery can take up to several years and decades, while coping with the actual hazard (rescuing survivors, establishing lifelines) will be much shorter, e.g. hours or several days, depending on the type and magnitude of the process. Wisner et al. (2004) accentuate time as a factor regarding succeeding disasters, because more vulnerable groups have longer recovery phases. If a hazard strikes again, without the recovery phase being completed, those people are even more vulnerable. This concept resembles the transient geosystem state described earlier.

Within the field of vulnerability research, spatial comparisons are common, conducted at different resolutions and spatial scales. Yet equally, vulnerability changes over time (Cutter, 1996b; Wisner, 1993; Wisner, 2003). This change might be related to, for example, better education, increased income and denser social networks. Alexander (2000) observes a metastable development of vulnerability, with a constant trend but interruptions; e.g. decreasing vulnerability after a new legislation is passed, yet only to be followed by uncontrolled development enhancing vulnerability. Examples of rising vulnerability associated with population increase appear frequently in the literature; see e.g. AndersonBerry (2003), who stresses that community vulnerability is dynamic. Keiler (2004) shows a significant increase in number and values of buildings, population and infrastructure between 1950 and 2000 for the town of Galtür, located in the Austrian Alps. This development reflects a general change from farming based activity towards a tourism-orientated economy, accompanied by social changes within the community. Time variation is one important aspect of vulnerability, however historical research is still sparse and the time element remains one of the most ignored issues of vulnerability (Cutter, 1996b, 2003a). Moreover, there is a lack of theo- retical exploration as to why positive and negative feedbacks evolve, increasing or decreasing vulnerability, respectively (Alexander, 2000).

Estimates of future development of vulnerability gain greater importance, generally accompanied with estimated higher losses because of increasing population and value of assets. Although protection measures might reduce shortterm losses, in the long-term vulnerability might be higher, because the protection measure attracts settlement and economic investment, hence vulnerability potential rises (Mileti and Myers, 1997), (see "risk transfer", Sect. 2.1.3). A global trend is apparent of more people being concentrated in urban areas and outgrowing their initially safe location. Population increase can enhance risk by leading to settlement and suburban sprawl in relatively unsuitable locations, such as steep slopes, volcanic areas or floodplains (geographic marginalization). In general, ability to access resources determines whether a risk is voluntary or involuntary. For economic reasons, people might be forced to select an unstable hillside for dwellings (involuntary) but freedom of choice can also result in exposure to risk (voluntary). The ability to choose is usually determined by the degree of vulnerability in terms of poverty and wealth (Wisner et al., 2004).

Global economic trends can also be associated with vulnerability. Growing wealth leads to a rise in quantity and value of property potentially at risk, but also allows more and effective options to reduce loss. Increasing poverty is a generator for vulnerability, influencing where and under which circumstances people live (see above), and whether they can afford insurance or measures to protect their homes. Combined with population growth infrastructure, such as transport and communication systems or other facilities, spreads or becomes more dense, thus making communities increasingly vulnerable (Mileti, 1999).

Since the vulnerability term is defined and understood in many different ways, the range of variables chosen to measure vulnerability is correspondingly large. However, differences in variables chosen to characterise vulnerability are not as extensive. The difference depends on whether a holistic approach is chosen or whether emphasis is laid either on the built environment or on social vulnerability. Exposure of people, buildings and lifelines is usually expressed by distance to the hazardous process (Cutter, 1996b), although the degree of exposure or interface is important, too. Characteristics of the built environment are often expressed by type of material and standards of design and construction. Since the 1970s, class, caste, ethnicity, gender, disability, education, wealth and age are seen as key factors of people's vulnerability (Smith, 2004). Vulnerability in terms of social networks, access to resources or political power is difficult to quantify. Therefore, social vulnerability is usually expressed by an individual's characteristics as listed above (Cutter et al., 2003b).

Vulnerability science needs to be more integrative, building on earth science, social science and anthropology (Cutter, 2003a). The "hazards-of-place model of vulnerability" combines "biophysical" and "social" vulnerability. The geo- 


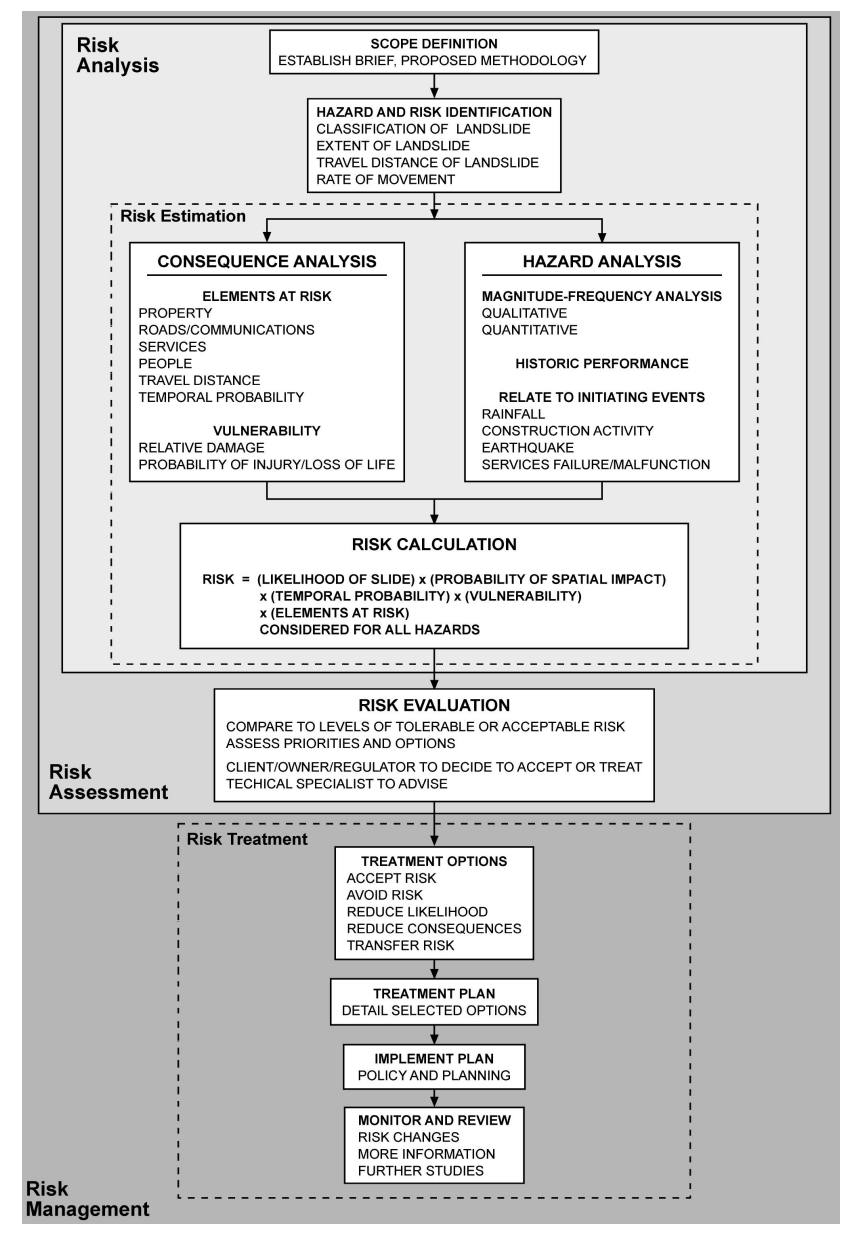

Fig. 3. The process of risk management (Crozier and Glade, 2005 after Australian Geomechanics Society, 2000).

graphic setting of a location influences the hazard, pronouncing or lessening the probability of a natural event with adverse effects. Simultaneously, the probability of adverse effects is also influenced by social constructions, like community experience and "ability to respond to, cope with, recover from and adapt to hazards, which in turn are influenced by economic, demographic, and housing characteristics" (Cutter et al., 2003b). Both, the biophysical and the social aspects of vulnerability produce the vulnerability of a place, addressing the need for a multidimensional way of thinking.

\subsubsection{Risk}

Risk is a measure of the probability of adverse effects on health, property and society, resulting from the exposure to a hazard of a given type and magnitude, within a certain time and area (Smith, 2004). The active part humans play is implied, but stressed by Renn (1992) who defines risk as "the possibility that an undesirable state of reality (adverse effects) may occur as a result of natural events or human activities", clearly including that "humans can and will make causal connections between actions (or events) and their effect, and that undesirable effects can be avoided or mitigated if the causal events or actions are avoided or modified".

In the 1980s, fuelled by considerations of technological hazards ("how safe is safe enough?"), the view of whole societies at risk ("risk society") and subsequently risk assessment emerged (Beck, 1986; Slovic, 2000). Risk analysis (scope definition, hazard and risk identification, plus risk estimation) is a precondition for risk assessment and subsequent risk management, and is starting to be adopted in national legislation (Australian Geomechanics Society, 2000), (Fig. 3). The quantitative risk assessment (QRA) is broadly used within the physical-science community (IUGS Working Group on Landslides - Committee on Risk Assessment, 1997). Within QRA, the risk equation $R=H \times E \times V$ described by Varnes (1984) according to UNDRO (1982) has gained international acceptance, with $R=$ risk, $H=$ hazard, $E=$ elements at risk and $V=$ vulnerability. "Elements at risk" are objects which possess the potential to be adversely affected, e.g. people, properties, infrastructure and economic activities including public services. Varnes (1984) defines "total risk" according to UNDRO (1982) as the "expected number of lives lost, persons injured, damage to property, or disruption of economic activity due to a particular natural phenomenon" (see also UNDRO, 1991). Since the 1990s, risk analysis is increasingly applied in the context of landslide studies and natural hazards. The quantitative assessment of risk is not always feasible, so qualitative risk estimations based on professional experience are used. Here, measures of "likelihood" of hazard occurrence range e.g. from "almost certain" to "not credible", and risk levels are expressed qualitatively and accompanied with a guide to their implications (Australian Geomechanics Society, 2000).

Since the concept of natural risk brackets a wide range of considerations, this formula might not include all of them. Nevertheless, its use is justified when its operationalisation is transparent and level of adverse affects and probabilities of geophysical process occurrence can be determined precisely (Bücking, 1994). However, some degree of uncertainty will always remain (Kröger, 2004).

Beliefs about the cause of a natural hazard and risk influence how people deal with them. The Lisbon earthquake 250 years ago destroyed nearly two-thirds of the town, triggering a theological and philosophical debate about the cause of this disaster. The Catholic Church regarded it as God's condemnation for sins and vanity, only to be avoided in the future by praying for forgiveness abjuring sins (Sanides-Kohlrausch, 2003). The perception of nature's forces being overwhelming, without the chance to withstand, still leads to a paralysis today (Weichselgärtner, 2001), rather than to active prevention measures. While the Catholic Church claimed its position after 1755 , it was strictly dismissed as cynical by philosophers Voltaire and Rousseau. Rousseau emphasised the human responsibility, since it was humans who built 20000 seven storey houses in high density. Immanuel Kant, who had studied many reports on earthquakes and drew on experience in Chile and Peru, clearly stated that building Lisbon in an earthquake-prone zone and not drawing on experiences elsewhere was the cause for the disaster (Sanides- 
Kohlrausch, 2003). Therefore, already in the 18th century it was recognised that human action causes disasters, and active, applicable strategies, like avoiding hazardous areas or applying different construction schemes, would have prevented the disaster or reduced its cost.

The quantification of risk by the scientific community, expressed in probability tables, is often not reflected in the perception of the public (Slovic, 2000). As Crozier ${ }^{1}$ revealed in a New Zealand case study, the same risk level expressed differently influences how people judge risk. Interpretation of risk information is complex and differs between societies (Lau, 2004), and individuals: prior knowledge, misconceptions and experience of hazard, as well as the way in which knowledge and beliefs are obtained vary.

Risk cannot be understood to be predominantly rational, since societies are not rational (Mileti, 2004). People judge a risk more by the degree it will affect their livelihood than by the mere physical process. Closing this gap should be an important objective of risk communication (Nathe et al., 1999; Paton, 2004). Associations with the notion of risk are highly variable, favouring misunderstandings amongst its users. Risks are perceived and assessed differently: The more benefit that can be gained by an activity, the less the risk is recognised and the more it is tolerated. Finally, there exists a schism about risk: on the one hand risk can relate to an individual, while on the other hand risk can be presented as a concern for the society (Bücking, 1994).

As emphasised earlier and as Tierney (1999) states, the level of natural risk changes constantly with time, because it depends on its dynamic contributors: natural hazard, elements at risk and their vulnerability. Society's capacity to cope is highly variable. Social-economic processes influencing the level of risk are likely to be subject to change, and can vary within very short time spans and over large areas (e.g. areas of new housing). As a consequence, no static state can be assumed. Understanding risk demands a model of fluxes. Cutter (2003a) states "We need dynamic - not static - models that integrate risk exposures with place-based biophysical and social indicators". Alexander (2000) points out that the lack of a retrospective perspective is a serious lapse within risk analysis. He sees the demand especially in the context of a rapidly changing world. Societies own a memory which transforms events into history. History influences culture, and finally culture provides the matrix for a society's reaction and perception following a natural disaster. Bücking (1994) identifies a positive relation between long-known risks and ascending reliability of risk estimation.

Natural risk mitigation and prevention strategies are also characterised by different time scales. While in cases of emergency immediate decision-making under pressure is needed, in the longer term it is crucial to recapitulate key processes and factors. Thus short-term, reductionistic structural strategies have their own value. However they are not

\footnotetext{
${ }^{1}$ Crozier, M. J., McClure, J., Vercoe, J., and Wilson, M.: The effects of land zoning information on judgments about earthquake damage, Environmental Hazards, submitted
}

adequate to deliver long-term, holistic non-structural mitigation strategies. Often, in natural hazard and risk management, more is done to delay losses than to erase them. A bias towards current problem solving exists, putting off "responsibilities to non-specific, non-existent future generations" (Stefanovic, 2003). Burton et al. (1978) introduced this phenomenon as "risk transfer": as a consequence of measures to reduce losses today, risk is transferred to an unknown point in future. Despite - or because of - the permanent development of protection measures, the death toll and economic loss is increasing globally (Alexander, 2000). While low-magnitude/high-frequency natural hazards might be well buffered, high-magnitude/low-frequency events are not. Thus, a false sense of security is created by short-term solutions. This perception is known by environmental psychologists as the "levee effect", meaning that people think the protection measure will save them from all future harm since it was constructed to match e.g. a certain flood magnitude - but which fails if projections are wrong or nature does not behave like expected (Bell et al., 1984).

Geosystem and social system change is likely to be nonlinear. However, as Mileti and Myers (1997) state for the US, a "traditional planning model" dominates which persists in its routine and is therefore linear and static.

While Tierney (1999) draws the conclusion that due to the constant flux, scenarios based on past observations are not sensible, we argue that although uncertainties exist, once the pattern of change is revealed (see Sect. 3), derived trends are useful and necessary for hazard and disaster management and preparedness. As pointed out earlier, geosystem response can be delayed due to long reaction and relaxation times - hence the actual cause is blurred by progress of time. This corresponds to the phenomenon of risk transfer and follows the same argument. A better sense of the actual risk level can be achieved when risk is assessed within its broader temporal context. However, static approaches dominate in risk research, focussing on calculating risk for a particular moment in time, but neglecting past and future development.

Societal interaction and complexity bring a range of greater benefits (economic, lifestyle), but also bear an increasing risk. A natural disaster is defined by Turner (1976) as "an event, concentrated in time and space, which threatens a society or a relatively self-sufficient subdivision of a society with major unwanted consequences". High impacts are to be considered if a disaster affects a big agglomeration of people and infrastructure within a global network of capital fluxes; an earthquake destroying Tokyo would entail damages of several thousands billions of dollars, with massive impact on the world economy (Kröger, 2004).

To face the responsibilities towards future generations at risk, the dynamics of the geosystem and social system and of their interconnections on longer time scales have to be addressed more effectively in risk research. 


\subsection{Connectivity and complexity}

As important as a dynamic approach is, a well balanced perspective of natural hazards, vulnerability and risk, acknowledging connectivity is a defining feature, and the need for a multi-disciplinary approach is crucial. Increasing connectivity is likely to result in higher complexity. Renn (1992) identifies multiple risk perspectives, based on several academic disciplines: the actuarial approach (using statistical predictions), the toxicological and epidemiological approach, the engineering approach (including probabilistic risk assessment PRA), the economic approach (including risk-benefit comparisons), the psychological approach (including psychometric analysis), social theories of risk and cultural theory of risk. Disciplines dealing with natural risk range from Meteorology, Engineering, Geology, Geophysics, Geography, Sociology, Environmental studies, Politics, Economics, Technology and Psychology (Etkin, 1999; Pohl and Geipel, 2002).

Natural risk research is inevitably more of a composite construct than some of its parent disciplines, who themselves borrow principles from the basic sciences. While basic sciences focus on single compartments, composite sciences are more integrative because they recognise connections between the compartments (Osterkamp and Hupp, 1996).

The demand to meet complexity of natural risk, and therefore diversity in research, imposes several challenges for the risk discipline. These are of general nature as well as topicspecific, as will be seen in the following.

Science aspires to be value-neutral. However, paradigms and attitudes shape the way we frame questions and therefore the answers we get; the methodology we use and the way we interpret data; topped by a non-linear implementation of research findings into policy. In natural risk research, perception can be positivistic or negativistic; experiments meet historical approaches, quantitative meet qualitative models and the same findings might be used for promoting different mitigation strategies (Stefanovic, 2003).

In very general terms, the natural risk concept is bilateral: earth science and social science follow different approaches, which are implicit in the previous discussion of vulnerability (Sect. 2.1.2.). With increasing adverse effects of soil erosion and flooding in the USA in the early 1930s, the ambition to reduce resulting losses by developing engineering works emerged. Geophysical processes were seen as the cause for disasters, which have to be controlled and predicted, usually with engineering measures and a "technical fix" philosophy. A broader point of view was stimulated by social geographer White (1945), who included non-structural measures in flood defence, watershed management and the role humans play. Decisions made are seen to create risk, rather than the physical process alone. Mismatching perception and fatalistic behaviour gained more attention within hazard mitigation. This limited human rationality ("bounded rationality"), e.g. settlement in floodplains, was the prominent paradigm (Beck, 1986; Wisner, 1993; Wisner et al., 2004). Nevertheless, solutions were still sought mainly in modelling, prediction and engineering, focussing on physical processes as the source of damage. With a combination of disaster planning and emergency preparedness, this set of measures gained high popularity and is often used today, known as the "behavioural paradigm". Burton et al. (1978) threw into the debate the question of how people choose which risk level is bearable. In the following years, economy, politics, geography, anthropology and psychology joined in natural hazards and risk research, shedding light on the differences between societies in terms of coping with and modifying the environment. However, research was still dominated by physical scientists and engineers, and a lack of prevention and mitigation measures (White and Haas, 1975).

In the 1970s, a counterpart of the behavioural paradigm developed, mainly due to a lack of success in reducing losses caused by natural hazards in less developed countries. This "structuralist paradigm" is advocated by social scientists active mainly in the less developed countries; especially in these countries disasters could not be explained sufficiently by the characteristics of the natural process alone. Other factors, linked with global economy, were identified which force people to become exposed to natural risk. A focus on societal structures as causes for disasters emphasises and progressively develops the concepts of poverty and vulnerability, tackling the most fundamental problems globally. Especially in the Third World, this paradigm was fed by issues of poverty, environmental exploitation and degradation. Inadequate resources were seen to increase vulnerability and therefore the degree of damage once a disaster strikes. Technological solutions were denied, instead a strong demand for fundamental changes of system organisations, including the distribution of wealth and power, dominated this paradigm, as well as a belief in local coping strategies (Smith, 2004).

Disaster preparedness and mitigation were the main purposes of the International Decade for Natural Disaster Reduction (IDNDR), which was hosted by the United Nations 1990-1999 and is still one of the main goals of its succeeding organisation International Strategy of Disaster Reduction (ISDR). Rather than focussing on disaster recovery, improved methods of disaster prediction, of early warning and disaster awareness became the focus of ISDR, coupled with strategies to lessen the burden of disasters on people and society (Cutter, 1996a).

In general, the end of the twentieth century reflects a dichotomy of the behavioural, hazard-focused paradigm and the structuralist paradigm, usually represented by earth scientists and social scientists, respectively.

As dynamic, connected and therefore complex systems emerge, resulting problems demand holistic solutions. The importance of integrative projects has been recognised, but few have been implemented. Addressing different causes for natural risk leads to different understandings, as well as the awareness of the limitations associated with specific discipline approaches. Since there are many disciplines involved, none of them can claim a central position (Tierney, 1999). A well-balanced approach to risk is needed, addressing both the 


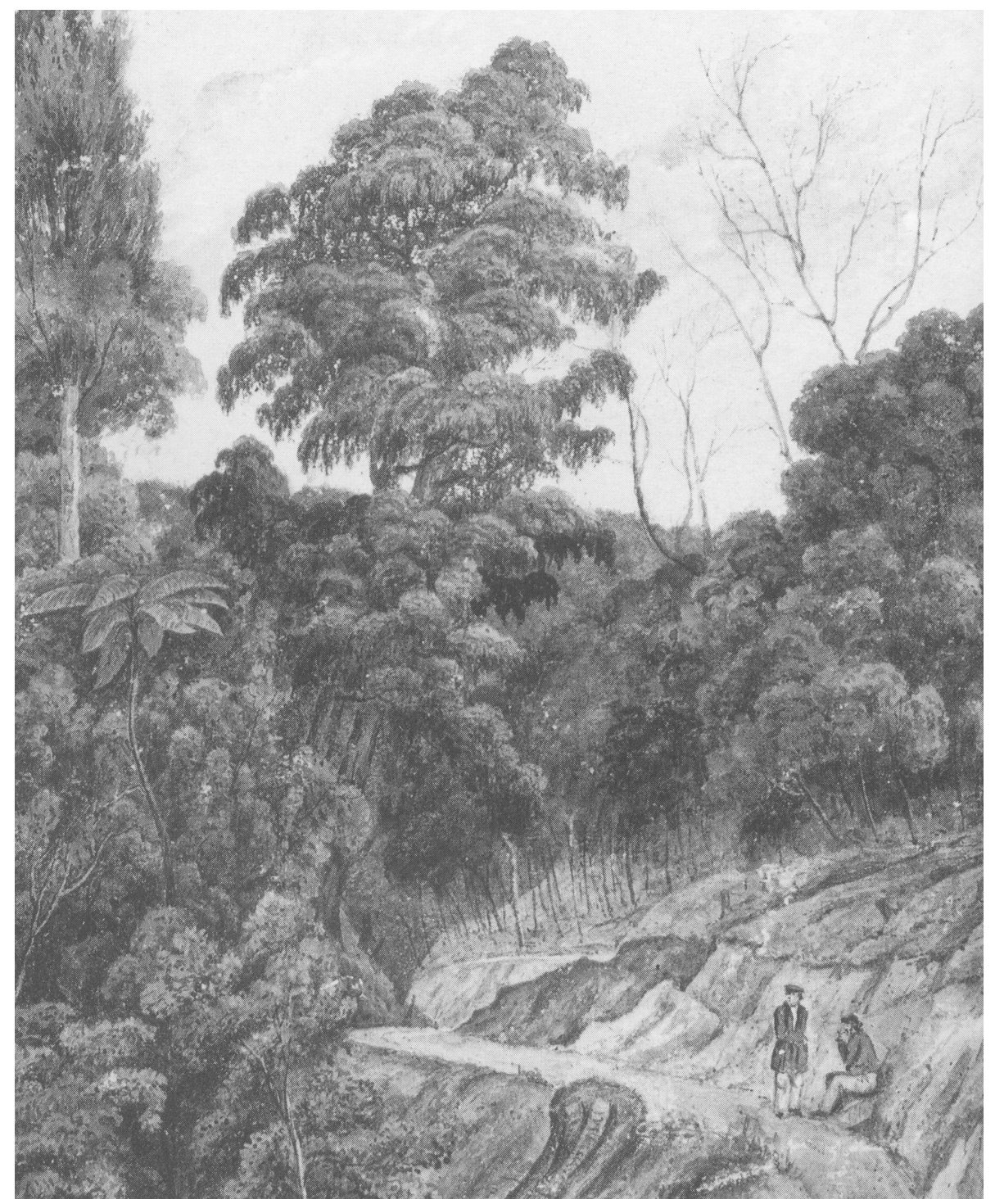

Fig. 4. Painting of W. M. Smith in 1842, showing a slip-prone road in the Wellington area. Intensive clearing of dense native bush was necessary for infrastructure and housing (McLean, 2000, Alexander Turnbull Library B-009-013).

natural process and humans as causes of risk. The challenge of the next decade is to join both paradigms.

Mileti and Myers (1997) introduce the idea of "sustainable hazard mitigation" which should replace the two different schools and is characterised by 1 . a broad approach and 2 . long-term perspectives to stop postponement of risk to future generations. Not only short-term loss reduction is envisaged, but also a long-term balance of geosystem and social system interaction. Non-linearity needs to be matched by flexible mitigation measures, and cross-discipline networks should be established. The need to address interactions between the systems and the way they change was again accentuated by Mileti (2004). The sustainable hazard mitigation concept has been taken up by the United Nations programme for hazard mitigation (Smith, 2004).

The concerns we have identified above have been echoed in the following plea from Johnston (1993): "Given the pre- dictions and forecasts that have been produced in recent years - from sober analysts, not from sensationalists - then greater efforts are needed to understand how the physical environment works (in part and, especially, as whole) and how those workings are influenced by what people do, so that we can be prepared for the worst-case scenarios of our potential environmental futures".

\section{New Zealand as the research context and proposed further study}

The concepts we have addressed in this paper will be explored in an ongoing research project based in New Zealand. We argue that New Zealand is an ideal location for such a study because of the recency and short period of both physical and social change within a highly hazardous environment. 

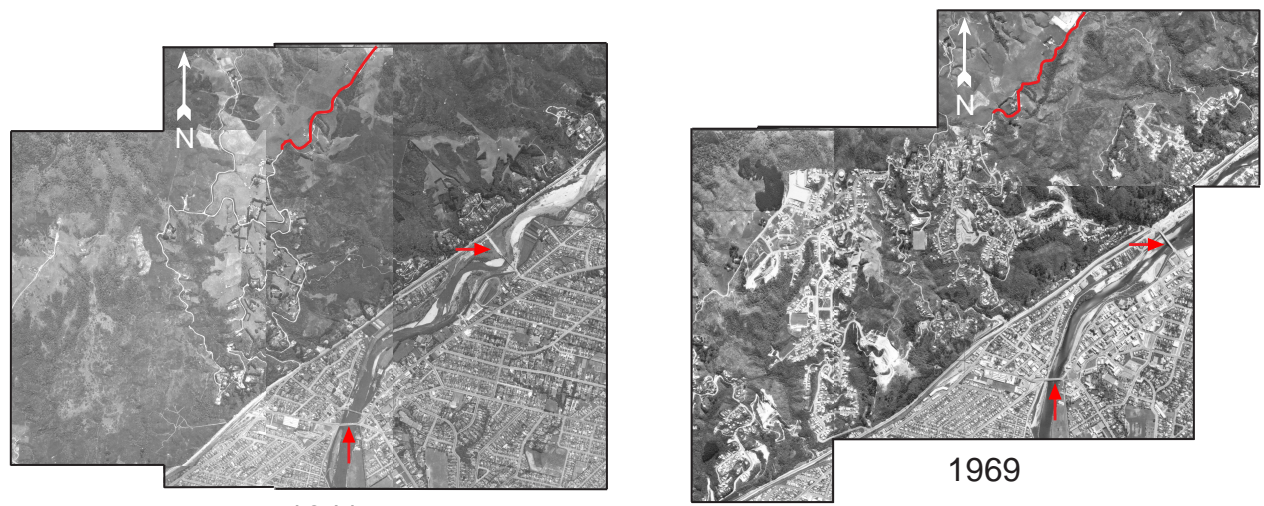

1941

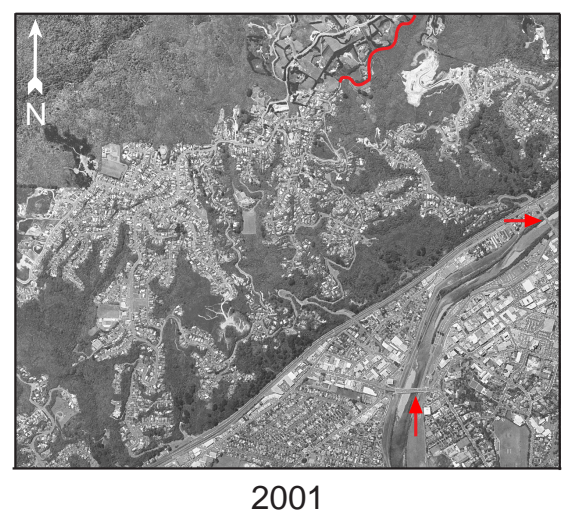

Fig. 5. Example of suburban sprawl showing the Western Hutt Hills next to Lower Hutt, Wellington Metropolitan Area, between 1941 and 2001 (from left to right: Maungaraki, Normandale, Harbour View; Hutt River crossing from north-east to south). Please note the arrows and lines marking points of reference.

In New Zealand, environmental and social changes have been dramatic over the last 150 years, due to rapid colonisation (Fig. 4), subsequent urbanisation and the development of land use, especially related to pastoral farming (Glade, 2003a).

Consequences are manifold and drastic in terms of landslide erosion and hazard. A post-war phase of prosperity, characterised by increasing population, suburbanisation and agricultural productivity, was replaced by the restructuring phase of the middle 1970s until the 1990s, which exerted massive changes on all sections of society, especially on land use. The farming sector was hit hard by cuts of subsidiaries and orientation on world market prices, resulting in profound changes in farming and related sectors (farm closure, farm amalgamation, change in base production and associated service industries). In 1991 the Resource Management Act (RMA) was passed, which replaced more than 60 other laws and imposed duties of environmental monitoring and managing upon the local government (Regional and District Councils) (King, 2003; Pawson et al., 1992). The RMA identifies sustainable management of natural and physical resources as its key concept. Natural and physical resources include land, water, air, soil, minerals and energy as well as all forms of plants and animals. Sustainable management in this context demands preserving "natural and physical resources to meet the reasonably foreseeable needs of future generations", and safeguards "the life-supporting capacity of air, water, soil and ecosystems". Regional Councils have to ensure "the control of the use of the land, including implementation of rules for the avoidance or mitigation of natural hazards" (RMA, 1991). Section 106 of the RMA defines denial of subdivision when land is likely to be affected by erosion, subsidence or slippage, unless satisfactory hazard avoidance or mitigation is assured. Additionally, the Building Act of 1991 states that territorial authorities are bound to hold data referring to potential erosion, falling debris, subsidence or slippage, which would have to be considered before building construction. The RMA and the Building Act have a profound implication for risk management in New Zealand. Effective risk reduction is defined as a government duty, and many of the Acts are successfully implemented because they are proactive and enabling. Special attention is paid to ensure landslide impacts on human activity are assessed, as well as the degree of human impact on land stability (Crozier, 2005).

The changes to land use in New Zealand during the last 50 years reflect temporal variations of physical, economic and political settings. In rural areas, such as the Gisborne district (East Coast, North Island) interaction of upper catchments and connected lowland, as well as the interaction of the social system and geosystem, are the main driving factors for 
temporal and spatial variation of landslide hazards and risk.

Urban areas are characterised by low density: Housing ideals today and during city planning have favoured separate single-storey houses with gardens (Pawson et al., 1992). Within the Wellington Metropolitan Area, suburbanisation, especially during the last 50 years, on the one hand and landslide-prone terrain on the other hand, produce a situation of landslide risk (Crozier and Aggett, 2000), (Fig. 5).

Tourism has increased significantly in New Zealand, reaching approximately more than 1 million tourists in 2002 (Tourism Research Council New Zealand, 2005). Tourism expenditure directly contributed $9.6 \%$ to GDP end of March 2003 , which is NZ \$ 16.5 billion. This is $34 \%$ higher than 1999 , and the annual percentage change compared to 2002 was 5.8 (Statistics New Zealand, 2004). The Tourism industry in New Zealand is now the largest export earner ahead of the dairy industry. Hot spots of tourism in New Zealand are mountainous regions, usually very active from a geomorphological perspective, such as the Mt. Cook Village (South Island).

The New Zealand examples demonstrate the need for a dynamic and holistic approach so we can better understand why and how risk changes through time. Both, geosystem and social system variability needs to be addressed equally. A study is being designed to explore the concepts discussed in this paper. The temporal variability of landslide risk for three different areas in New Zealand (Gisborne, Wellington, Mt. Cook Village as described above) will be extracted via multi-temporal analysis of various data sets. Further, if risk level is shown to vary significantly with time, this ongoing research aims to reveal the causes and to assess implications for future risk management.

Based on the conceptual framework presented so far, we have identified the following hypothesis for ongoing research: In the long-term, natural risk changes inevitably, continuously and irreversibly in the sense of "evolution". Subsequent research questions are:

1. Can short-term periods of equilibrium be identified? Which kind of equilibrium dominates?

2. Which implications can be made use of for future risk level estimation?

3. What are the respective roles of geo- and social system, in influencing the level of risk?

\section{Summary}

Two observations shape the conceptual framework presented: 1 . natural risk is variable in time and 2. connectivity of physical and social systems is a main characteristic of natural risk. However, both aspects are not represented sufficiently in current risk research.

Time is a crucial consideration in natural hazard analysis, as shown by using landslides as an example. Landslide history, the function of variables, observational time span and geosystem sensitivity play important roles for natural process behaviour and probability assessment. Natural processes are complex phenomena displaying interaction with humans and their built environment. Elements at risk and their vulnerability vary through time, since they reflect changes in societies. Risk, as a synthesis of all three agents, is therefore variable in time. The understanding of and approaches to risk are not uniform. The variety of disciplines involved imposes great challenges for those involved in risk management.

In New Zealand, the geosystem and social system changed rapidly after colonisation 150 years ago. The last 50 years in particular have experienced a phase of accelerated change, revealing the interactions of both systems. Therefore, the New Zealand examples clearly show that a dynamic and holistic approach to natural risk is needed. A multi-temporal study is being designed to investigate the temporal variation of landslide risk in New Zealand for three different areas, each representing processes of national importance (rural development, urban development, tourism).

To accept the responsibilities towards future generations at risk, the dynamics of the geosystem and social system and their interactions on longer time scales have to be addressed more effectively in risk research. The analysis of past risk levels and underlying processes holds the potential to support risk management, which has to deal with the current situation and possible future developments of both the geo- and the social system.

Acknowledgements. The authors would like to thank the German Academic Exchange Service (Deutscher Akademischer Austausch Dienst, DAAD) and Victoria University of Wellington Postgraduate Targeted Scholarship for supporting this research. Special thanks to S. Pritchett, R. Willis and T. Vowles for suggestions during and after manuscript preparation. Additionally, many thanks to J. Coe and the anonymous reviewer for their helpful comments.

Edited by: F. Guzzetti

Reviewed by: J. Coe and another referee

\section{References}

Adams, D.: The Hitchhiker's guide to the galaxy, Harmony Books, New York, 224, 1989.

Alexander, D. E.: Confronting catastrophe, Oxford University Press, New York, 282, 2000.

Anderson-Berry, L. J.: Community Vulnerability to Tropical Cyclones: Cairns, 1996-2000, Natural Hazards, 30, 209-232, 2003.

Australian Geomechanics Society: Landslide risk management concepts and guidelines, Australian Geomechanics, 49-92, 2000.

Beck, U.: Risikogesellschaft, Auf dem Weg in eine andere Moderne, Suhrkamp, Frankfurt/M., 396, 1986.

Bell, P. A., Fisher, J. D., Baum, A., and Greene, T. E.: Environmental Psychology, Holt, Rinehart and Winston Inc., Fort Worth, 1984.

Brunsden, D. and Thornes, J. B.: Landscape sensitivity and change, The Institute of British Geographers, Transactions, New Series, 4, 436-484, 1979. 
Bücking, E.: Risk. One Term, Many Perceptions and Assessments, Universitas, 3, 188-198, 1994.

Burton, I., Kates, R. W., and White, G. F.: The Environment as Hazard, Oxford University Press, Oxford, 240, 1978.

Butzer, K. W.: Civilizations: Organisms or Systems?, in: Human Geography, An essential Anthology, edited by: Agnew, J., Livingstone, D. N., and Rogers, A., Blackwell Publishers Ltd., Oxford, UK, Malden, USA, 268-281, 1996.

Chorley, R. J.: Geomorphology and general system theory, Theoretical Papers in the Hydrologic and Geomorphic Papers. Geological Survey Professional Paper, United States Government Printing Office, Washington, B1-B9, 1962.

Chorley, R. J. and Kennedy, B. A.: Physical Geography, A System Approach, Prentice Hall International Inc., London, 1971.

Chorley, R. J., Schumm, S. A., and Sudgen, D. E.: Geomorphology, London, New York, 605, 1984.

Christaller, W.: Central places in Southern Germany. Prentice-Hall, New York, London, 1966.

Crozier, M. and Aggett, G.: A hazardous place, in: Dynamic Wellington, edited by: McConchie, J., Winchester, D., and Willis, R., Institute of Geography, Wellington, 137-154, 2000.

Crozier, M. J.: Landslides: causes, consequences and environment, Croom Helm, London, 252, 1986.

Crozier, M. J.: Management Issues Arising from Landslides and Related Activity, New Zealand Geographer, 49, 1, 35-37, 1993.

Crozier, M. J.: Landslides, in: Encyclopedia of environmental science, edited by: Alexander, D. E. and Fairbridge, R. W., Kluwer, Dordrecht, 371-375, 1999.

Crozier, M. J.: Management Frameworks for Landslide Hazard and Risk: Issues and Options, in: Landslide hazard and risk, edited by: Glade, T., Anderson, M. G., and Crozier, M. J., Wiley, Chichester, 331-350, 2005.

Crozier, M. J. and Glade, T.: Frequency and magnitude of landsliding: fundamental research issues, Zeitschrift für Geomorphologie, Suppl.-Bd. 115, 141-155, 1999.

Crozier, M. J. and Glade, T.: Landslide Hazard and Risk: Issues, Concepts and Approach, in: Landslide Hazard and Risk, edited by: Glade, T., Anderson, M. G., and Crozier, M. J., Wiley, Chichester, 1-40, 2005.

Crozier, M. J. and Preston, N.: Modelling Changes in Terrain Resistance as a Component of Landform Evolution in Unstable Hill Country, in: Process Modelling and Landform Evolution, edited by: Hergarte, S. and Neugebauer, H. J., Springer, 267-284, 1998.

Cruden, D. M. and Varnes, D. J.: Landslide types and processes, Landslides-Investigation and Mitigation, Special Report, National Academy Press, Washington, D.C., 36-75, 1996.

Cutter, S. L.: Societal response to environmental hazards, Blackwell Publishers, Oxford UK, Cambridge USA, 525-536, 1996 a.

Cutter, S. L.: Vulnerability to environmental hazards, Progress in Human Geography, 20, 4, 529-539, 1996b.

Cutter, S. L.: The Vulnerability of Science and the Science of Vulnerability, Annals of the Association of American Geographers, 93, 1, 1-12, 2003a.

Cutter, S. L., Boruff, B. J., and Shirley, W. L.: Social Vulnerability to Environmental Hazards, Social Science Quarterly, 84, 2, 242261, 2003b.

Davis, W. M.: The geographical cycle, Geographical Journal, 14, 481-504, 1899.

Davis, W. M.: The geographical cycle, in: Geographical Essays, edited by: Johnson, D. W., Dover Publications, 249-278, 1909.

Dikau, R., Brunsden, D., Schrott, L., and Ibsen, M. (eds.): Landslide Recognition. Identification, movement and causes, John
Wiley \& Sons Ltd, Chichester, 251, 1996.

Etkin, D.: Risk transference and related trends: Driving forces towards more mega-disasters, Environmental Hazards, 1, 2, 69-75, 1999.

Gilbert, G. K.: Report on the Geology of the Henry Mountains, U.S. Geographical and Geological Survey of the Rocky Mountain Region, U.S. Government Printing Office, Washington, D.C., 170, 1877.

Glade, T.: Establishing the frequency and magnitude of landslidetriggering rainstorm events in New Zealand, Environmental Geology, 35, 2-3, 160-174, 1998.

Glade, T.: Modelling landslide-triggering rainfalls in different regions of New Zealand - the soil water status model. Zeitschrift für Geomorphologie, Suppl.-Bd. 122, 63-84, 2000.

Glade, T.: Landslide hazard assessment and historical landslide data - an inseparable couple?, in: The use of historical data in natural hazard assessments, edited by: Glade, T., Frances, F., and Albini, P., Advances in Natural and Technological Hazards Research, Kluwer Academic Publishers, Dordrecht, 153-168, 2001.

Glade, T.: Landslide occurrence as a response to land use change: a review of evidence from New Zealand, Catena, 51, 297-314, 2003a.

Glade, T.: Vulnerability Assessment in Landslide Risk Analysis, Die Erde, 134, 2, 123-146, 2003b.

Goudie, A. S.: Land Transformation, in: The Challenge for geography: a changing world, a changing discipline, edited by: Johnson, R. J., Blackwell Publishers, Oxford, UK; Cambridge, USA, 117-137, 1993.

Graf, W. L.: Fluvial Processes in Dryland Rivers, Springer, Berlin, Heidelberg, 346, 1988.

Hack, J. T.: Interpretation of erosional topography in humid temperate regions, Am. J. Sci, 258-A, 80-97, 1960.

Haigh, M. J.: The holon: Hierarchy theory and landscape research, Catena, Suppl. 10, 181-192, 1987.

IUGS Working Group on Landslides - Committee on Risk Assessment: Quantitative assessment for slopes and landslides - The state of the art, in: Landslide risk assessment - Proceedings of the Workshop on Landslide Risk Assessment, Honolulu, Hawaii, USA, 19-21 February 1997, edited by: Cruden, D. M. and Fell, R., A.A. Balkema, Rotterdam, 3-12, 1997.

Johnston, R. J.: A Changing World: Introducing the Challenge, in: The Challenge for geography: a changing world, a changing discipline, edited by: Johnson, R. J., Blackwell Publishers, Oxford, UK, Cambridge, USA, 3-31, 1993.

Keiler, M.: Development of the damage potential resulting from avalanche risk in the period 1950-2000, case study Galtür, Nat. Haz. Earth Sys. Sci., 4, 249-256, 2004,

\section{SRef-ID: 1684-9981/nhess/2004-4-249.}

King, M.: The Penguin History of New Zealand, Penguin Books Ltd., Aukland, 570, 2003.

Koestler, A.: The Ghost in the Machine, MacMillan, New York, 384, 1967.

Kröger, W.: Minirisiko, Riesenaufwand, Die Zeit, 36, 2004.

Lau, J.: Abschied von der Panikmache, Die Zeit, 35-36, 2004.

Leilich, J.: Mind and value, in: Is nature ever evil? Religioin, Science and Value, edited by: Dress, W. B., Routledge, London, New York, 32-40, 2003.

McLean, G.: Wellington: the first years of european settlement 1840-1850, Penguin Books, Aukland, 96, 2000.

Mileti, D.: Disasters by Design. A reassessment of natural hazards in the United States, The Joseph Henry Press, Washington DC, 1999. 
Mileti, D.: Keynote lecture: Towards a resilient society: turning research into policy and programmes for sustainable hazard mitigation, 6th New Zealand Natural Hazards Management Conference "From Science to Practice", Tauranga, New Zealand, 2004.

Mileti, D. and Myers, M. F.: A bolder course for disaster reduction: imagining a sustainable future, Revista Geofisica, 47, 41$58,1997$.

Nathe, S., Gori, P., Greene, M., Lemersal, E., and Mileti, D.: Public education for earthquake hazards, Natural Hazards Informer, 2, 1999.

Omar, H. and Alon, N.: The continuity principle: A unified approach to disaster and trauma, American Journal of Community Psychology, 22, 273-287, 1994.

Osterkamp, W. R. and Hupp, C. R.: The Evolution of Geomorphology, Ecology, and Other Composite Sciences, in: The scientific nature of geomorphology: proceedings of the 27th Binghamton Symposium in Geomorphology, held 27-29 September, 1996, edited by: Rhoads, B. L. and Thorn, C. E., John Wiley and Sons, Chichester, 415-441, 1996.

Pacione, M.: Urban Geography. Routledge, London, New York, 663, 2001.

Paton, D.: Keynote Address, Preparing for Disaster: Integrating risk, resilience and vulnerability perspectives, in: Vulnerable Communities and Emergencies, edited by: Pool, T., Proceedings of the Emergency Management Conference 2004, Melbourne, 2004.

Paton, D., Johnston, D., Bebbington, M., Lai, C.-D., and Houghton, B.: Napier City Council Hazard Analysis Research project, Part 2: Social vulnerability, Lower Hutt, New Zealand, 2003.

Pawson, E., Roche, M., Johnson, R., Banks, G., Morgan, R., Holland, P., Hearn, T., Scott, G., and Horsley, P.: The environment, in: Changing Places in New Zealand, edited by: Britton, S., Le Heron, R., and Pawson, E., A Geography of Restructuring. New Zealand Geographical Society (Inc.), Christchurch, 187214, 1992.

Pohl, J. and Geipel, R.: Naturgefahren und Naturrisiken, Geographische Rundschau, 54, 1, 4-8, 2002.

Preston, N.: Event-induced changes in landsurface condition - implications for subsequent slope stability, Zeitschrift für Geomorphologie, Suppl.-Bd. 115, 157-173, 1999.

Reid, L. M. and Page, M. J.: Magnitude and frequency of landsliding in a large New Zealand catchment, Geomorphology, 49, 71-88, 2002.

Reimer, W.: Keynote paper: landslides and reservoirs, in: Landslides - Proceedings of the sixth international symposium on landslides, edited by: Hell, D. H., Christchurch, February 1992, Rotterdam, 1995.

Renn, O.: Concepts of risk: a Classification, in: Social Theories of Risk, edited by: Krimsky, S. and Golding, D., Praeger, Westport, 1992.

RMA: Resource Management Act, Wellington, Government Printer, 1991.

Sanides-Kohlrausch, C.: The Lisbon Earthquake, 1755, A discourse about the "nature" of nature, in: Is nature ever evil? Religion, Science and Value, edited by: Dress, W. B., Routledge, London, New York, 106-119, 2003.

Sassen, S.: Cities in a World Economy, Pine Forge Press, Thousand Oaks, California, 157, 1994.

Schumm, S. A.: The fluvial System, John Wiley and Sons, New York, 1977.

Schumm, S. A.: Geomorphic thresholds: the concept and its applications, The Institute of British Geographers, Transactions New
Series, 4, 485-515, 1979.

Schumm, S. A.: To interprete the Earth. Ten ways to be wrong, Cambridge University Press, 1991.

Schumm, S. A.: The Fluvial System. The Blackburn Press, Caldwell, USA, 2003.

Schumm, S. A. and Lichty, R. W.: Time, space and causality in geomorphology, American Journal of Science, 263, 110-119, 1965.

Slovic, P.: Perception of Risk, in: The perception of risk, edited by: Löfstedt, R. E., Earthscan, London, 220-315, 2000.

Smith, K.: Environmental hazards: Assessing risk and reducing disaster, Routledge, London, New York, 306, 2004.

Spencer, H.: The Study of sociology, University of Michigan Press, 1961, 411, 1872.

Spengler, O. and Atkinson, C. F.: The decline of the West, A. A. Knopf, New York, 1926.

Statistics New Zealand: Tourism Satellite Account 2000-2003, Statistics New Zealand, Wellington, 38, 2004.

Stefanovic, I. L.: The Contribution of Philosophy to Hazards Assessment and Decision Making, Natural Hazards, 28, 229-247, 2003.

Thomas, M. F.: Landscape sensitivity in time and space - an introduction. Catena, 42, 83-98, 2001.

Tierney, K. J.: Toward a Critical Sociology of Risk, Sociological Forum, 14, 2, 215-242, 1999.

Tobin, G. A.: Sustainability and community resilience: the holy grail of hazards planning?, Environmental Hazards, 1, 1, 13-25, 1999.

Tourism Research Council New Zealand: http://www.trenz.govt. nz/Topics/Visitor+Arrivals+and+Departures/Inbound+Travel, 2005.

Turner, B. A.: The development of disasters: a sequence model for the analysis of the origin of disasters, Sociological Review, 24, 753-754, 1976.

UNDRO: Natural disasters and vulnerability analysis, United Nations Disaster Relief Organisation, Geneva, 1982.

UNDRO: Mitigation natural disasters, Phenomena, Effects and options, United Nations Disaster Relief, New York, 1991.

Varnes, D. J.: Landslides hazard zonation: a review of principles and practice, UNESCO, Paris, 63, 1984.

von Bertalanffy, L.: The theory of open systems in physics and biology. Science, 111, 3, 23-29, 1950.

Weichselgärtner, J.: Disaster mitigation: the concept of vulnerability revisited, Disaster Prevention and Management, 10, 2, 85-94, 2001.

White, G. F.: Human adjustment to floods: a geographical approach to the flood problem in the United States, Research Paper, 29, Chicago, 1945.

White, G. F. and Haas, J. E.: Assessment of Research on Natural Hazards, The MIT Press Environmental Studies Series, London, 487, 1975.

Wisner, B.: Disaster Vulnerability: Scale, Power and Daily Life, GeoJournal, 30, 2, 127-140, 1993.

Wisner, B.: Social Planning and Activism for Earthquake Risk Reduction in Megacities: the Cases of Mexico City and Los Angeles, Petermanns Geographische Mitteilungen, 147, 4, 32-39, 2003.

Wisner, B., Blaikie, P., Cannon, T., and Davis, I.: At Risk - Natural hazards, people's vulnerability and disasters. Routledge, London, 471, 2004.

Wolman, M. G. and Miller, J. P.: Magnitude and frequency of forces in geomorphic processes, J. Geol., 68, 54-74, 1960.

Wright, R.: A short history of progress, Anansi, 208, 2004. 